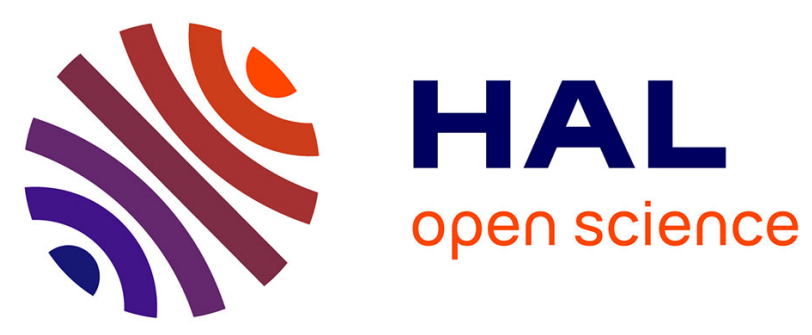

\title{
Active Microwave Circuit With Negative Group Delay
} Blaise Elysée Guy Ravelo, André Pérennec, Marc Le Roy, Yann G. Boucher

\section{To cite this version:}

Blaise Elysée Guy Ravelo, André Pérennec, Marc Le Roy, Yann G. Boucher. Active Microwave Circuit With Negative Group Delay. IEEE Microwave and Wireless Components Letters, 2007, 17, pp.861863. 10.1109/LMWC.2007.910489 . hal-00461783

\section{HAL Id: hal-00461783 \\ https://hal.univ-brest.fr/hal-00461783}

Submitted on 8 Mar 2010

HAL is a multi-disciplinary open access archive for the deposit and dissemination of scientific research documents, whether they are published or not. The documents may come from teaching and research institutions in France or abroad, or from public or private research centers.
L'archive ouverte pluridisciplinaire HAL, est destinée au dépôt et à la diffusion de documents scientifiques de niveau recherche, publiés ou non, émanant des établissements d'enseignement et de recherche français ou étrangers, des laboratoires publics ou privés. 


\title{
Active Microwave Circuit With Negative Group Delay
}

\author{
Blaise Ravelo, André Pérennec, Marc Le Roy, and Yann G. Boucher
}

\begin{abstract}
In this letter, we report on the design, simulation and implementation of an active negative group delay circuit that operates at $1 \mathrm{GHz}$ with a group delay and a gain, respectively, around $-2 \mathrm{~ns}$ and $2 \mathrm{~dB}$. Analytical formulas are proposed to demonstrate that the adopted topology is able to simultaneously achieve negative group delay (NGD) and gain while fulfilling active device constraints. The theoretical and simulated results are both validated by frequency measurements of a two-stage active microwave circuit.
\end{abstract}

Index Terms-Active devices, negative group delay (NGD).

\section{INTRODUCTION}

$\mathbf{F}$ OR numerous applications, particularly in modern highspeed telecommunications, flat group delay or linear phase is necessary to avoid distortion in the baseband signals. In the microwave domain, group delay equalizers are used to compensate for group delay variations mostly introduced by filters [1] or amplifiers [2]. Time delay variations are also known to cause instabilities in feedback circuits in oscillator applications [3].

To reduce such perturbations, Lucyszyn et al. [3], [4] have put forward an original negative group delay synthesizer. This narrow band Microwave Integrated Circuit synthesizer, built with varactors, field effect transistors (FET) and lumped components, operates in reflection and needs a coupler to pass into transmission. High negative group delay (NGD) values are obtained at $1 \mathrm{GHz}$ but also with high losses. Since this first proposal in microwave domain, several topologies exhibiting negative group delay have been proposed and we can merge these devices in two categories according to their operating frequency domain. The first one, essentially devoted to the microwave domain, is composed of passive left-handed media (LHM) built with $R L C$ parallel resonant and high-pass $L-C$ networks [5]. Nevertheless, to achieve a significant NGD value, many cells have to be cascaded resulting in a very low transmission level caused by resonant absorption losses. The second category is only devoted to very low frequencies (below a few hundred $\mathrm{kHz}$ ) and these circuits, built with operational amplifiers and lumped components [6], [7] have been mainly designed to lay down the general principles of NGD and as

Manuscript received April 2, 2007; revised August 29, 2007.

B. Ravelo, A. Pérennec, and M. Le Roy are with the Laboratoire d'Electronique et Systèmes de Télécommunication (LEST-UMR CNRS 6165), Université de Bretagne Occidentale, Brest 29238, France (e-mail: ravelo@univbrest.fr; marc.leroy@univ-brest.fr; andre.perennec@univ-brest.fr).

Y. G. Boucher is with the Ecole Nationale d'Ingénieurs Brest (ENIB/RESO), Brest F-29238, France.

Color versions of one or more of the figures in this paper are available online at http://ieeexplore.ieee.org.

Digital Object Identifier 10.1109/LMWC.2007.910489 demonstrators to illustrate higher frequency experiments. These electronic circuit approaches present gain and NGD simultaneously but can not be transposed into the microwave domain due to the component bandwidth limitations.

To design a NGD circuit suitable for microwave applications, we propose, in this letter, a new active topology that produces NGD with loss compensation. To achieve these objectives while meeting active device requirements, we have tested several topologies, and for the adopted solution, we show analytically the NGD existence and present the design equations. Then, the implementation in microstrip technology of a two-stage circuit, that operates around $1 \mathrm{GHz}$, is described. Simulation and experimental frequency results are compared and discussed.

\section{Active Device Topology With NeGative GROUP DELAY}

To compensate for the inherent losses of passive circuits with NGD, active components, such as a FET, must be associated with passive elements. But, an active device at microwave frequencies must simultaneously meet the specifications of gain, input and output return losses, noise factor in the passband, and stability at any frequencies. In this context, the notion of topology is of paramount importance.

These considerations led us, first, to try to associate the wellknown NGD passive circuits [5], [8], and particularly the $R L C$ parallel network in cascade or in shunt with an FET. We also looked for a possible interaction between the transistor and the passive elements while keeping the target topology as simple as possible. But finally, among many investigated topologies, an FET cascaded with a series $R L C$ network (Fig. 1) appears to be the most suitable one to meet all the requirements. First, the FET is represented by its low frequency model, i.e., the transconductance, $g_{m}$, and the drain-source resistor, $R_{\mathrm{ds}}$. The group delay is defined by differentiating the $S_{21}$ parameter phase versus angular frequency, $\tau=-\partial \angle S_{21} / \partial \omega$. Then, at the $R L C$ resonance frequency, $\omega_{0}=1 / \sqrt{L C}$

$$
\tau\left(\omega_{0}\right)=\frac{-2 L Z_{0} R_{\mathrm{ds}}}{R \cdot\left[R R_{\mathrm{ds}}+Z_{0}\left(R+R_{\mathrm{ds}}\right)\right]} .
$$

$Z_{0}$ is the input impedance of the reference ports (50 $\Omega$ in practice). At the resonance, the group delay is always negative and proportional to $L$. The scattering parameters are given by

$$
\begin{aligned}
& S_{21}\left(\omega_{0}\right)=\frac{-2 R Z_{0} g_{m} R_{\mathrm{ds}}}{R_{\mathrm{ds}} R+Z_{0}\left(R+R_{\mathrm{ds}}\right)} \\
& S_{22}\left(\omega_{0}\right)=\frac{R_{\mathrm{ds}} R-Z_{0}\left(R+R_{\mathrm{ds}}\right)}{R_{\mathrm{ds}} R+Z_{0}\left(R+R_{\mathrm{ds}}\right)} .
\end{aligned}
$$

The NGD occurs at the resonance where the $S_{21}$ parameter is minimum. As $R$ decreases, the NGD value increases and conse- 


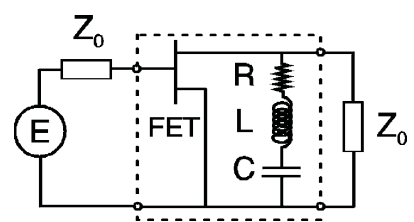

Fig. 1. Series $R L C$ resonant network cascaded in shunt with an FET.

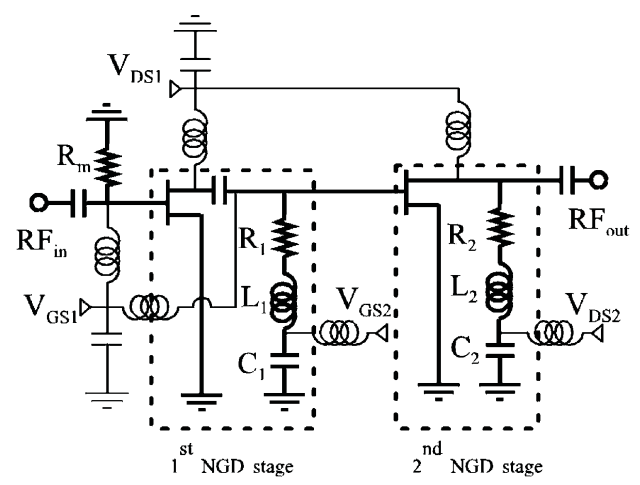

Fig. 2. Two-stage ideal circuit with bias networks in thin lines.

quently $S_{21}$ is also lowered. The group delay of the series $R L C$ network in shunt, on its own, can be expressed versus its quality factor, $Q$

$$
\tau_{R L C}\left(\omega_{0}\right)=\frac{-2 Q Z_{0}}{\omega_{0}\left(2 R+Z_{0}\right)}
$$

For the active cell (Fig. 1), this expression is modified as

$$
\tau_{\text {cell }}\left(\omega_{0}\right)=\frac{-2 Q Z_{0}}{\omega_{0}\left(R+R \cdot Z_{0} / R_{\mathrm{ds}}+Z_{0}\right)} .
$$

From (1) and (5), it becomes evident that increasing $L$ improves $Q$ and thus the NGD value while narrowing the resonance band and reducing the NGD bandwidth. Moreover, in (5), if $R_{\mathrm{ds}}$ is higher than $Z_{0}$, the negative group delay value can be slightly improved in the active topology. These equations force us to give priority to an FET with high $g_{m}$ and $R_{\mathrm{ds}}$ values and in that case a compromise between low $R$ and high $L$ values may be found to achieve gain and an NGD value. These explanations may be partially summed up by the following ratio:

$$
\frac{\left|S_{21}\left(\omega_{0}\right)\right|}{\left|\tau_{\text {cell }}\left(\omega_{0}\right)\right|}=\frac{g_{m} R^{2}}{L} .
$$

From (3), output matching may also be obtained for a high $R_{\mathrm{ds}}$ value and a not too small $R$ value (toward $Z_{0}$ ). Input matching can simply be done with a shunt resistor $R_{m}$ (Fig. 2) at the FET input. Then, the input return loss is simply expressed as

$$
S_{11}\left(\omega_{1}\right)=\frac{R_{m}-Z_{0}}{R_{m}+Z_{0}}
$$

And at the resonance, the transmission parameter is modified as follows:

$$
S_{21}\left(\omega_{1}\right)=-\frac{2 R_{m} R_{1} Z_{0} g_{m} R_{\mathrm{ds}}}{\left(R_{m}+Z_{0}\right)\left(Z_{0} R_{\mathrm{ds}}+Z_{0} R_{1}+R_{1} R_{\mathrm{ds}}\right)} .
$$

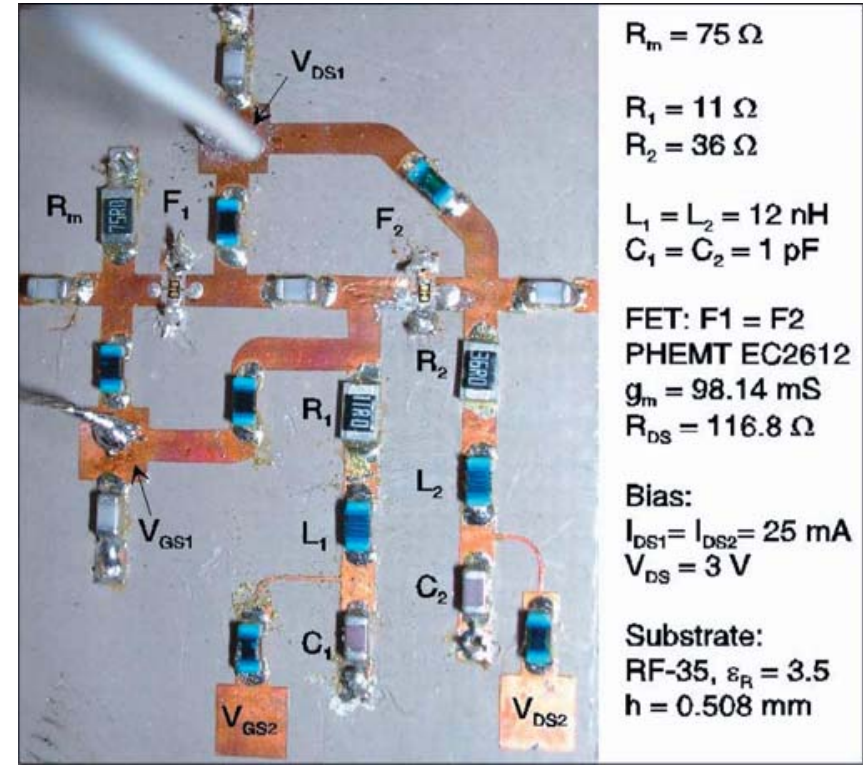

Fig. 3. Photograph of the two-stage NGD circuit with the component values.

\section{CIRCUIT IMPLEMENTATION AND EXPERIMENTAL RESUlTS}

To validate the concept of active device with NGD, we built a circuit operating at centimetric wavelengths to avoid too many high frequency parasitic effects and to stay in the validity domain of the FET model. A two stage device ensures that all our objectives could be reached with a significant margin, i.e., at least a group delay below $-2 \mathrm{~ns}$, gain around 2 or $3 \mathrm{~dB}$ and input/output matching below $-10 \mathrm{~dB}$. Then, from these values and by inverting (1), (3), (7), and (8), the component values can be calculated for the specified FET. If both stages resonate at the same frequency, the total insertion losses and group delay are expressed as

$$
\begin{aligned}
S_{21 T} & =\frac{S_{21_{1}} S_{21_{2}}}{1-S_{22_{1}} S_{11_{2}}} \\
& =\frac{2 g_{m}^{2} R_{\mathrm{ds}}^{2} R_{1} R_{2} Z_{0} R_{m}}{\left(R_{1}+R_{\mathrm{ds}}\right)\left(Z_{0}+R_{m}\right)\left(R_{2} Z_{0}+Z_{0} R_{\mathrm{ds}}+R_{\mathrm{ds}} R_{2}\right)} \\
\tau_{T} & =\tau_{1}+\tau_{2}-\frac{2 L R_{\mathrm{ds}}^{2}}{\left(R_{1}+R_{\mathrm{ds}}\right)\left(R_{1} R_{\mathrm{ds}}+R_{1} Z_{0}+R_{\mathrm{ds}} Z_{0}\right)}
\end{aligned}
$$

where the index 1, 2 an $T$ correspond, respectively, to the first and second stages and to the overall circuit. Finally, the electromagnetic simulation (ADS Momentum software) shows responses really close to the results obtained from our analytical low frequency model except for a slight shift in the resonance frequency. First, we biased the circuit ( $V_{\mathrm{GS} 1}$ and $V_{\mathrm{DS} 1}$ in Figs. 2 and 3 ) in a traditional way for both the gates and the drains. Fig. 4 compares the EM simulation results to measurements for the scattering parameters and the group delay. These results were obtained with no adjustment. One should note the good agreement between simulations and measurements, especially for the gain and the group delay values that reach respectively $1.68 \mathrm{~dB}$ and $-2.3 \mathrm{~ns}$ with matching better than $10 \mathrm{~dB}$. The slight 


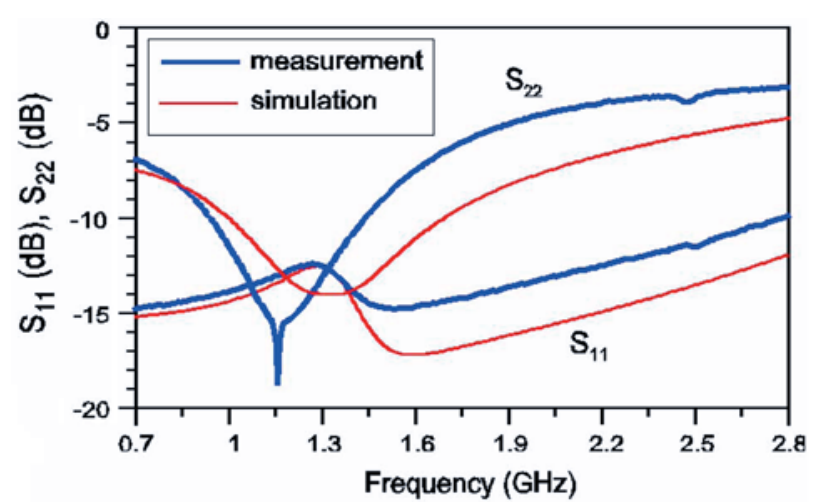

(a)

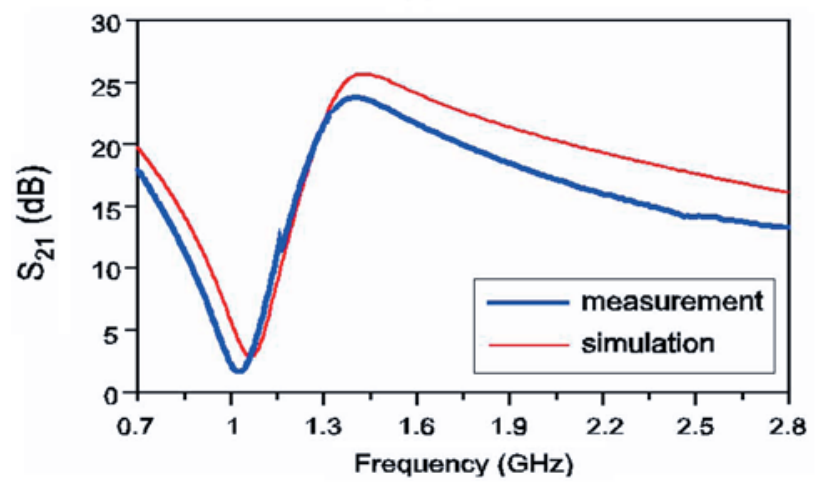

(b)

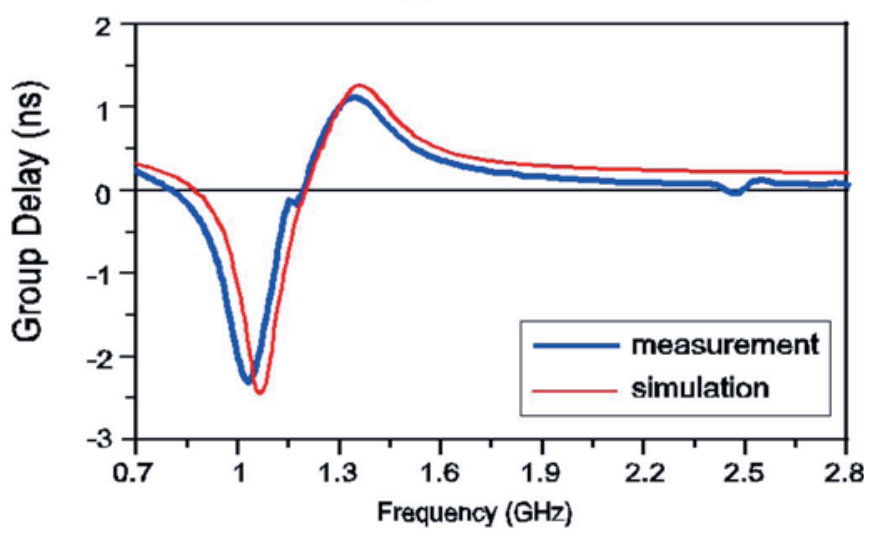

(c)

Fig. 4. (a), (b) Measured and simulated $S$-parameters and (c) group delay.

shift in the frequency measurements is fully explained by the $L$ and $C$ component tolerances (see Fig. 4).

We obtain a better agreement compared with the passive circuits operating at a similar frequency band [5], a higher NGD value is reached with fewer cells and the NGD bandwidth is slightly improved while meeting all the active design requirements. We further biased the transistors between $L_{1}$ and $C_{1}$ and between $L_{2}$ and $C_{2}$ through the high value inductors ( $V_{\mathrm{GS} 2}$ and $V_{\mathrm{DS} 2}$ in Figs. 2 and 3). Under this configuration, the results of the second set of measurements were exactly the same as the first ones. So, the $R L C$ networks ensure two functions and the whole circuit could be simplified.

\section{CONCLUSION}

An active circuit showing NGD and gain simultaneously is, for the first time, designed and implemented at microwave frequencies. Measurements are really close to those expected from our analytical equations and, at $1 \mathrm{GHz}$, a $2 \mathrm{~dB}$ gain is associated with a -2 ns group delay. This topology may also be transposed to higher frequency bands with a more complete FET modelling and by passing $R L C$ lumped components into distributed planar technology. Tunable capacitances and inductances could be used separately or together to control either the frequency or the level of the NGD. Moreover, stages with different resonant frequencies would produce broadband NGD suitable for ultra wideband (UWB) applications and for baseband numerical signals in inter- or intra-chip interconnects.

\section{REFERENCES}

[1] H. T. Hsu, H. W. Yao, K. A. Zaki, and A. E. Atia, "Synthesis of coupled-resonators group-delay equalizers," IEEE Trans. Microw. Theory Tech., vol. 50, no. 8, pp. 1960-1968, Aug. 2002.

[2] K. Murase, R. Ishikawa, and K. Honjo, "Group delay compensation technique for UWB MMIC using composite right/left-handed circuit," in Proc. Asia-Pacific Microw. Conf., Yokohama, Japan, 2006, pp. 1409-1412.

[3] S. Lucyszyn, I. D. Robertson, and A. H. Aghvami, "Negative group delay synthesiser," Electron. Lett., vol. 29, no. 9, pp. 798-800, Apr. 1993.

[4] S. Lucyszyn and I. D. Robertson, "Analog reflection topology building blocks for adaptative microwave signal processing applications," IEEE Trans. Microw. Theory Tech., vol. 43, no. 3, pp. 601-611, Mar. 1995.

[5] O. F. Siddiqui, M. Mojahedi, and G. V. Eleftheriades, "Periodically loaded transmission line with effective negative refractive index and negative group velocity," IEEE Trans. Antennas Propag., vol. 51, no. 10, pp. 2619-2625, Oct. 2003.

[6] T. Nakanishi, K. Sugiyama, and M. Kitano, "Demonstration of negative group delays in a simple electronic circuit," Amer. J. Phys., vol. 70, no. 11, pp. 1117-1121, 2002.

[7] D. Solli and R. Y. Chiao, "Superluminal effects and negative delays in electronics, and their applications," Phys. Rev. E, no. 5, pp. 56601. 1-056601.4, Nov. 2002.

[8] V. Eleftheriades, A. K. Iyer, and P. C. Kremer, "Planar negative refractive index media using periodically L-C loaded transmission lines," IEEE Trans. Microw. Theory Tech., vol. 50, no. 12, pp. 2702-2712, Dec. 2002. 